\title{
NAPHTHAQUINONE PIGMENTS FROM TORULA HERBARUM: STRUCTURE OF O-METHYLHERBARIN*
}

\author{
N. NARASImhaChari** and K. S. Gopalkrishnan \\ Antibiotics Research Center \\ Pimpri, Poona 18, India
}

(Received for publication November 16, 1973)

\begin{abstract}
A third naphthaquinone pigment isolated from Torula herbarin is now identified as O-methylherbarin by IR, NMR and mass spectroscopic methods. The structure is confirmed by partial synthesis by methylation of herbarin using methyl iodide and silver oxide. The gas chromatographic-mass spectrometric characteristics of herbarin, dehydroherbarin and $\mathrm{O}$-methylherbarin are described.
\end{abstract}

In previous papers the isolation of two naphthaquinone pigments, herbarin (Ia) and dehydroherbarin (II) from Torula herbarum ${ }^{1,2)}$ was reported and their structures were described. Both thin-layer (TLC) and gas-liquid chromatography (GLC) of the mixture of pigments revealed the presence of other minor components. One of these minor pigments, described as "fraction 5", was obtained in small quantities by preparative TLC. Fraction 5 was crystalized from ethyl acetate from which it separated as yellow needles and prisms which melt at $188 \sim 190^{\circ} \mathrm{C}$. The UV and visible spectrum of this product (Fig. 1) was almost identical with that of herbarin $\left(\lambda_{\max } 218,267,285 \mathrm{sh}\right.$ and $\left.415 \mathrm{~nm}\right)$. The infrared spectrum in chloroform solution was also very similar to that of herbarin, but it did not show any hydroxyl absorption. Unlike herbarin, the compound was readily soluble in $\mathrm{CDCl}_{3}$ and gave a good NMR spectrum (Fig. 2) which afforded information on its structure. The spectrum as in herbarin showed two aromatic protons (meta), two methoxyls, a $\mathrm{CH}_{3}$ and two $\mathrm{CH}_{2}$ groups. The spectrum did not show any hydroxyl proton but instead showed a third methoxyl group (6.72 $\tau)$ (see Fig. 2 for assignments).

The mass spectrum obtained by direct introduction of sample on a solid probe into the ion source showed the molecular ion $(\mathrm{P})$ at $m / e$ 318 and the fragment ions at $m / e$ $303\left(\mathrm{P}-\mathrm{CH}_{3}\right)^{+}, \quad 286\left(\mathrm{P}-\mathrm{CH}_{3} \mathrm{OH}\right)^{+}$, $271\left(\mathrm{P}-\mathrm{CH}_{3} \mathrm{OH}-\mathrm{CH}_{3}\right)^{+}, \quad 244 \quad(\mathbf{P}-$ $\left.\mathrm{CH}_{3} \mathrm{COOCH}_{3}\right)^{+}$and $243\left(\mathrm{P}-\mathrm{CH}_{3} \mathrm{OH}-\right.$ $\left.\mathrm{CH}_{3} \mathrm{CO}\right)^{+}$. On the basis of these spectroscopic data the compound is assigned the structure of O-methylherbarin (Ib). This structure was confirmed by partial synthesis of

Fig. 1. UV and visible spectrum of O-methylherbarin.

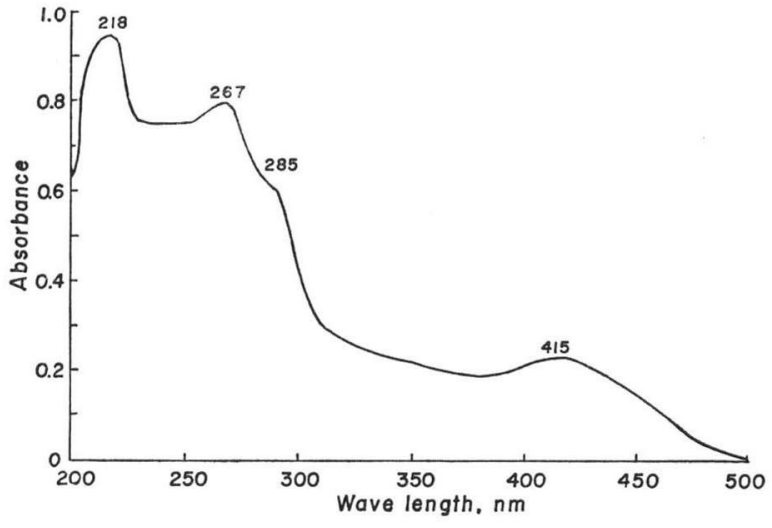

* A preliminary report was published in the Proceedings of the International Symposium on the Chemistry of Natural Products (IUPAC), New Delhi, February 1972, pp. 477 478.

** Present address: Galesburg State Research Hospital, Galesburg, Illinois 61401, U.S.A. 
Fig. 2. NMR spectrum of $\mathrm{O}$-methylherbarin in $\mathrm{CDCl}_{3}$.

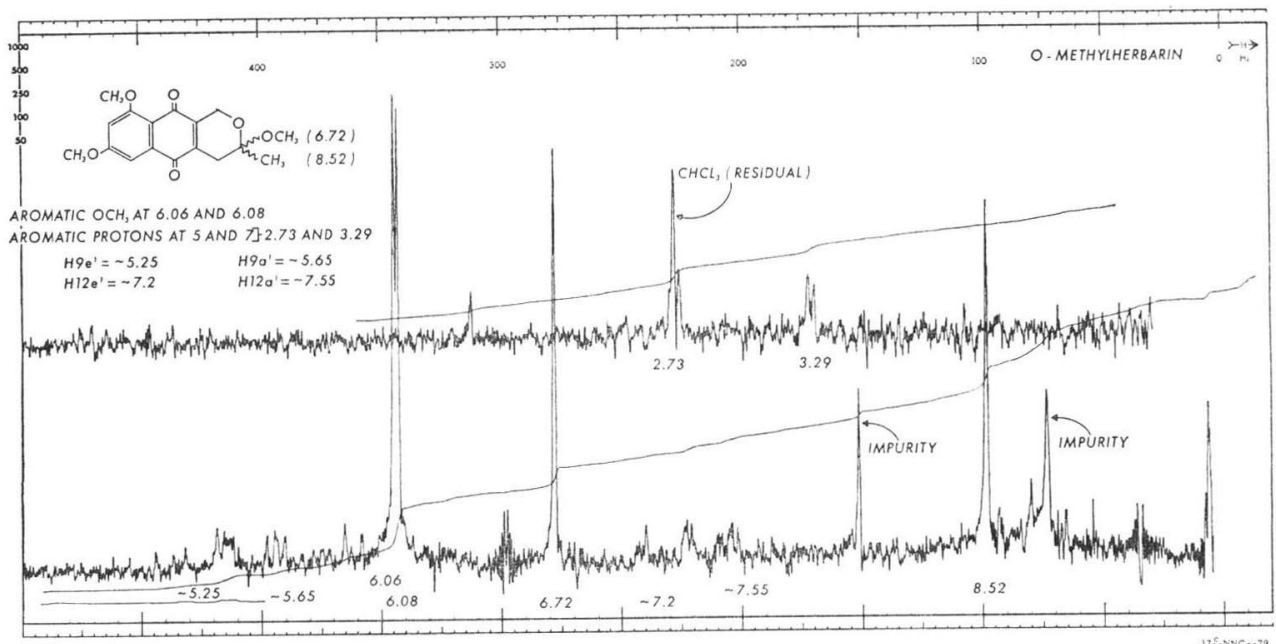

Fig. 3. Gas-liquid chromatograms of natural herbarin, O-methylherbarin and synthetic O-methylherbarin. (3\% OV-101 on gaschrom Q 6-ft column $210^{\circ}$ iso $\mathrm{N}_{2} 40 \mathrm{ml} / \mathrm{min}$ ).

Herbarin and O-methylherbarin (natural)

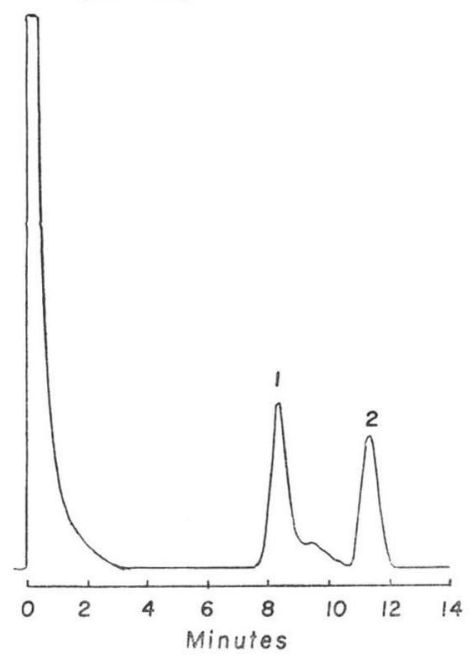

O-Methylherbarin from herbarin

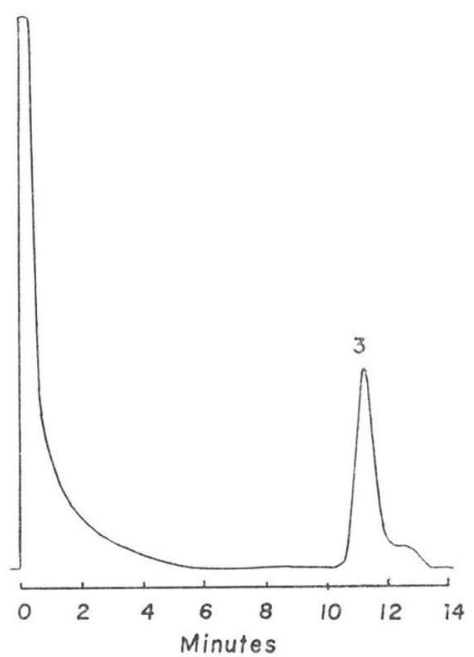

this compound from herbarin (Ia) by refluxing it with methyl iodide and silver oxide in a solution of methylene chloride. The UV, IR, NMR and mass spectra of the synthetic and natural products were identical. The identity was further confirmed by TLC and GLC. Gasliquid chromatograms of natural herbarin, O-methylherbarin and synthetic $\mathrm{O}$ methylherbarin are shown in Fig. 3 .

\section{Gas-liquid Chromatography-Mass Spectrometry (GC-MS)}

Gas-liquid chromatography was done on a 6-ft, $3 \%$ OV-101 on GCQ column at $210^{\circ} \mathrm{C}$ isothermal with $\mathrm{N}_{2}$ as the carrier gas at a flow-rate of $40 \mathrm{ml} / \mathrm{min}$ on a Barber Colman 5700 instrument. Both herbarin and dehydroherbarin had the same retention time ( 8 minutes 18 seconds) suggestng the possible dehydration of herbarin (Ia) to dehydro compound (II). This was confirmed by GC-MS where both herbarin and dehydroherbarin gave identical mass spectra corresponding to structure II. O-Methylherbarin had a retention time of 11 minutes 15 seconds and the mass spectrum was identical with that obtained on direct solid sample probe. The GC-MS data were obtained on a Varian $\mathrm{CH}-7$ mass spectrometer interfaced with a Varian 2740 gas chromatograph, 
ionization potential $70 \mathrm{eV}$, source temperature $280^{\circ} \mathrm{C}$, separator temperature $300^{\circ} \mathrm{C}$ and helium flow-rate $30 \mathrm{ml} / \mathrm{min}$.

Mass-spectral Characteristics of

\section{Herbarins}

The mass spectra of dehydroherbarin (II), herbarin (Ia) and O-methylherbarin (Ib) are shown in Figs. 4, 5 and 6 . Of these, high resolution data were also obtained for herbarin. While the fragmentations are those generally expected of the naphthaquinone structure, some special features are worthy of mention. The base peak in dehydroherbarin is $\left(\mathrm{M}-\mathrm{CH}_{3}\right)^{+}$ at $m / e$ 271, while in herbarin the base peak is at $m / e 286$, the $(\mathrm{M}-18)^{+}$ion, and in $\mathrm{O}$ methylherbarin the base peak is at m/e 244 by loss of $\mathrm{CH}_{3} \mathrm{COOCH}_{3}$ from the molecular ion. The fragment ions in the spectra at $m / e 244$ in herbarin and O-methylherbarin and at $m / e$ 243 in dehydroherbarin arise by a similar mechanism as shown in the scheme.

The fragmentation mechanism is confirmed by the distinct metastable ions ( $\mathrm{m}^{*} 195.8$ and 187.2) seen in the mass spectra of $\mathbf{I a}$ and $\mathbf{I b}$. Similarly the other fragmentations for the three structures are supported by appropriate metastable transitions noted in the spectra. These are given in Table 1.

Another feature in the spectra of these compounds, which could be used for their identification by GC-MS, is the appearance in all three spectra of doubly charged ions of high intensity at $m / e 121.5$ and 129.5 , and of ions at $m / e 135.5$ and 151.5 in the spectrum of O-methylherbarin. 


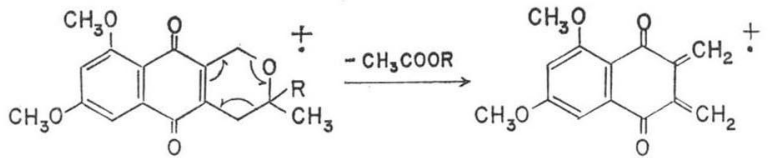

la $R=O H$

Ib $\mathrm{R}=\mathrm{OCH}_{3}$<smiles>[CH+]=C1C(=C)C(=O)C(=O)c2c(OC)cc(OC)cc2C1=O</smiles>

\section{Experimental}

A solution of herbarin $(20 \mathrm{mg})$ in methylene chloride $(100 \mathrm{ml})$ was refluxed with methyl iodide $(1 \mathrm{ml})$ and silver oxide $(1 \mathrm{~g})$ for 12 hours. The mixture was filtered, the solids were washed with $10 \mathrm{ml}$ of methylene chloride and the filtrate plus washings was evaporated under vacuum. TLC on silica gel $G$ showed that the major portion of the product was O-methylherbarin with traces of unreacted

Table 1. Metastable transitions in the mass spectra of herbarin derivatives and the parent and daughter ions

\begin{tabular}{|c|c|c|c|}
\hline Compound & Parent $m / e$ & Daughter $m / e$ & Metastable $\mathrm{m}^{*}$ \\
\hline \multirow[t]{7}{*}{ Herbarin } & $304^{a}$ & 286 & 269.3 \\
\hline & 286 & 271 & 256.6 \\
\hline & 304 & 276 & 250.8 \\
\hline & 304 & 244 & 195.8 \\
\hline & 286 & 258 & 232.4 \\
\hline & 243 & 215 & 190.2 \\
\hline & 271 & 243 & 217.9 \\
\hline \multirow[t]{4}{*}{ Dehydroherbarin } & $286^{a}$ & 271 & 256.4 \\
\hline & 271 & 243 & 217.9 \\
\hline & 243 & 215 & 190.2 \\
\hline & 243 & 228 & 213.9 \\
\hline \multirow[t]{7}{*}{ O-Methylherbarin } & $318^{a}$ & 303 & 288.7 \\
\hline & 318 & 286 & 257.2 \\
\hline & 318 & 244 & 187.2 \\
\hline & 286 & 271 & 256.6 \\
\hline & 271 & 243 & 217.9 \\
\hline & 243 & 215 & 190.2 \\
\hline & 215 & 187 & 162.5 \\
\hline
\end{tabular}

a Molecular ion.

herbarin. After purification by preparative TCL on silica gel $G$, the fast moving band corresponding to O-methylherbarin was eluted with chloroform-methanol $(1: 1)$. The residue obtained after evaporation was used directly for TLC, GLC and spectroscopic analysis. The TLC, GLC, UV, IR and mass spectral characteristics of the methylated product were identical to those of natural O-methylherbarin.

\section{Acknowledgement}

We thank Dr. R. NAGARAJAN of Lilly Research Laboratories, Indianapolis, for providing the NMR and mass spectra of the compounds. 


\section{References}

1) Kadkol, M. V.; K.S. Gopalkrishnan \& N. Narasimhachari: Isolation and characterization of naphthaquinone pigments from Torula herbarum (PERs). Herbarin and dehydroherbarin. J. Antibiotics 24: 245 248, 1971

2) Nagarajan, R.; N. Narasimhachari, M. V. Kadkol \& K. S. Gopalkrishnan: Structure of herbarin. J. Antibiotics 24: 249 252, 1971 